\title{
An Invitation of the Combination of the Geriatric Nutritional Risk Index and the Triglyceride to High-Density Lipoprotein Cholesterol Ratio as a Mortality Predictor in Maintenance Hemodialysis Patients
}

\author{
Ayako Hasegawa', Norio Hanafusa'2, Masayuki Okazaki' ${ }^{3}$, Mizuki Komatsu ${ }^{3}$, \\ Hiroshi Kawaguchi' ${ }^{3}$, Ken Tsuchiya ${ }^{2}$, Kosaku Nitta ${ }^{*}$ \\ ${ }^{1}$ Department of Medicine, Kidney Center, Tokyo Women's Medical University, Tokyo, Japan \\ ${ }^{2}$ Department of Blood Purification, Kidney Center, Tokyo Women's Medical University, Tokyo, Japan \\ ${ }^{3}$ Department of Nephrology, Jyoban Hospital, Fukushima, Japan \\ Email: *knitta@twmu.ac.jp
}

How to cite this paper: Hasegawa, A., Hanafusa, N., Okazaki, M., Komatsu, M., Kawaguchi, H., Tsuchiya, K. and Nitta, K. (2017) An Invitation of the Combination of the Geriatric Nutritional Risk Index and the Triglyceride to High-Density Lipoprotein Cholesterol Ratio as a Mortality Predictor in Maintenance Hemodialysis Patients. International Journal of Clinical Medicine, 8, 86-97.

https://doi.org/10.4236/ijcm.2017.82008

Received: January 11, 2017

Accepted: February 20, 2017

Published: February 23, 2017

Copyright (๑) 2017 by authors and Scientific Research Publishing Inc. This work is licensed under the Creative Commons Attribution International License (CC BY 4.0).

http://creativecommons.org/licenses/by/4.0/

(c) (i) Open Access

\begin{abstract}
Background: The geriatric nutritional risk index (GNRI) has been developed as a tool to assess the nutritional risk. The triglyceride to high-density lipoprotein cholesterol (TG/HDL-C) ratio has been shown to be a predictor of cardiovascular (CV) outcomes in the general population. Objectives: The aim of this study was to determine whether the combination of GNRI and TG/HDL-C ratio is a predictor of all-cause mortality and CV deaths in maintenance hemodialysis (MHD) patients. Methods: We performed a retrospective, observational cohort study in which we enrolled $341 \mathrm{MHD}$ patients from a single center in Japan who had been followed up for a mean of $48.0 \pm 12.7$ months. The outcomes were defined as the occurrence of all-cause mortality and CV deaths during the follow-up period. Baseline GNRI and TG/HDL-C ratios were investigated for associations with outcomes by using Cox proportion hazards models adjusted for demographic parameters. Results: Overall, 101 of the subjects had died, of whom 52 died due to CV events during the mean follow-up period of $48.0 \pm 12.7$ months. The patients were grouped into four categories according to a median GNRI $<95.3$ or $\geq 95.3$ and a median TG/HDL-C ratio $<2.09$ or $\geq 2.09$. The group with a GNRI $\geq 95.3$ and TG/ HDL-C $\geq 2.09$ had significantly lower overall and CV mortality rate when compared with the other three groups. Conclusion: The combination of GNRI and TG/HDL-C ratio is an easily accessible marker for predicting allcause mortality and CV deaths in MHD patients.
\end{abstract}




\section{Keywords}

GNRI, Triglyceride, HDL-Cholesterol, Mortality, Hemodialysis

\section{Introduction}

The geriatric nutritional risk index (GNRI), based on body weight, height and serum albumin level, has been identified as a simple method to evaluate nutritional condition of patients. Previous studies have demonstrated the reliability of GNRI in assessing malnutrition [1] and in predicting all-cause mortality in maintenance hemodialysis (MHD) patients [2] [3]. However, despite the significance of the GNRI on mortality in MHD patients in Western countries, the role of the GNRI on the nutritional condition has not been fully evaluated in Asian MHD patients.

Dyslipidemia, in which there is a combination of a high TG level and low HDL-C level, has been reported to strongly predict cardiovascular (CV) morbidity-coronary artery disease, in particular in the general population [4] [5]. Several studies have demonstrated a correlation between the TG to HDL-C (TG/ HDL-C) ratios and both the severity of insulin resistance and presence of coronary atherosclerotic lesions in the general population [6] [7]. The TG/HDL-C ratio has been shown to predict the occurrence of myocardial infarction, ischemic heart disease [8] [9], and CV mortality, both in women with coronary artery disease and in the general population [10] [11].

The aim of this study was to determine if the combination of GNRI and TG/ HDL-C ratio is a possible predictor of all-cause mortality and CV deaths in MHD patients.

\section{Methods}

\subsection{Subjects and Protocol}

This was a retrospective, observational cohort study conducted at a single center in Japan. The subjects were recruited from patients who had been routinely treated using an arteriovenous fistula in the dialysis unit of the Jyoban Hospital, Fukushima, Japan for at least 6 months. The Institutional Review Board of the Jyoban Hospital approved all study protocols, and they were performed in accordance with the Declaration of Helsinki guidelines regarding ethical principles for medical research involving human subjects. Informed consent was obtained from all of the subjects.

HD patients with malignancy, active inflammation, liver cirrhosis, gastrointestinal bleeding, cardiac valvular disease, or severe illness were excluded from participation and were transferred to another dialysis unit for intensive care. The patients who were enrolled as subjects $(\mathrm{n}=341)$ underwent stable regular HD with a bicarbonate dialysate. Their underlying diseases of end-stage renal disease were diabetic nephropathy $(\mathrm{n}=170)$, chronic glomerulonephritis $(\mathrm{n}=154)$, hypertensive nephrosclerosis $(n=70)$, polycystic kidney disease $(n=8)$, and 
chronic pyeonephritis $(n=3)$, or unknown origin $(n=6)$.

All patients were on thrice-weekly HD and no further selection was performed in patients. All of the subjects had an arteriovenous fistula. None of the subjects had residual renal function (urine volume $\geq 100 \mathrm{~mL} /$ day). Blood pressure (BP) was measured with a mercury sphygmomanometer with the patient in the supine position after resting for 10 to 15 minutes, and mean values for the 1 -month period preceding enrollment were used in the statistical analysis. Dry weight was targeted to achieve a normotensive edema-free state. Previous cardiovascular disease and smoking status were collected from medical records. Diabetes was defined as a history or presence of diabetes and/or a fasting plasma glucose concentration $>126 \mathrm{mg} / \mathrm{dl}$ or $\mathrm{HbAlc}$ concentration $>6.5 \%$ or prescription of glucose-lowering agents.

Blood samples were taken prior to the first-week dialysis session day, following an overnight period without the consumption of food. Serum urea nitrogen, creatinine, calcium, phosphorous, albumin, total cholesterol, and C-reactive protein (CRP) levels and the hemoglobin concentration were measured with an autoanalyzer by standard laboratory methods. Total calcium was corrected for by the patient's albumin level. Intact parathyroid hormone (iPTH) was measured by an immunoradiometric assay. The body mass index (BMI) was expressed in $\mathrm{kg} / \mathrm{m}^{2}$. Weight was calculated as dry weight, defined as post-dialysis weight in which the patient was normotensive and with no signs of overhydration. Urea kinetics were assessed by measuring a blood-based dialysis parameter, $\mathrm{Kt} / \mathrm{V}$ [12], and the mean value of the 3 measurements during each of the three months before the beginning of the study was used in the analysis. The normalised protein catabolism rate (nPCR) was used as an indirect indicator of protein intake and was obtained using the following formula as previously described [13].

The GNRI was calculated by modifying the Nutritional risk index for elderly patients, as reported by Yamada et al. [1] as follows:

GNRI $=[14.89 \times$ albumin $(\mathrm{g} / \mathrm{dl})]+[41.7 \times($ body weight $/$ ideal body weight $)]$.

For body weight, we considered the value at the end of the dialysis session, and it was also used for the calculation of BMI. Body weight/ideal body weight was set to 1 when the body weight of the patient exceeded the ideal body weight [14]. The ideal body weight in the present study was calculated using height and a BMI of 22, which is reportedly associated with the lowest morbidity rate in the Asian population [14].

Data for endpoints were obtained from hospital charts and through telephone interview with the patients, conducted by trained but double-blind interviewers. The primary endpoint of the study was all-cause mortality during the follow-up period between July 1, 2011 and July 31, 2016. The secondary endpoint was cardiovascular death, including those due to heart failure, myocardial infarction, arrhythmia, sudden death, and stroke. The vital status of the subjects was determined by searching the electronic dialysis records. Patients were censored if they were alive on July $31,2016$. 


\subsection{Statistical Analysis}

Normally distributed, unpaired continuous values were expressed as means $\pm \mathrm{SD}$ and compared by performing an Analysis of Variance (ANOVA). Nonparametric values were expressed as median values and compared by performing the Kruskal-Wallis test. Categorical values were expressed as percentages and compared by performing the Fisher's exact test.

The survival analysis was based on the Kaplan-Meier curve with subjects censored for death. A log-rank test was used to compare the survival rates of two groups. A multivariate Cox proportional hazards model with adjustment for multivariate factors was used to evaluate mortality risk. Results were expressed as a hazard ratio (HR) with $95 \%$ confidence intervals (CIs). A significant level of p value $<0.05$ was assumed to be statistically significant. All statistical analyses were performed by using the SAS version 9.2 software program (SAS Institute Inc., Cary, NC, USA) for Windows personal computers.

\section{Results}

Of the 341 included patients, we stratified the patients into four groups according to a median GNRI $<95.3$ or $\geq 95.3$ and a median TG/HDL-C ratio $<2.09$ or 22.09. A comparison of the clinical characteristics of these groups is shown in Table 1. Compared to the patients with a GNRI $<95.3$ (TG/HDL-C $\geq 2.09$ or TG/HDL-C $<2.09$ ), those with a GNRI $>95.3$ (TG/HDL-C $\geq 2.09$ or TG/HDL-C $<2.09$ ) were older, had lower values of BMI, hemoglobin, serum phosphorus and albumin, and higher CRP values.

\subsection{Risk of All-Cause Mortality}

Overall, the mean follow-up period was $48.0 \pm 12.7$ months. During the followup period, 101 patients died (29.6\%), including 52 due to CV diseases, 38 due to infectious diseases, 6 due to malignancy, and 5 due to gastrointestinal bleeding. Table 2 lists the HRs of variables for all-cause mortality. The univariate regression analysis shows that the group with a GNRI $\geq 95.3$ and TG/HDL-C $\geq 2.09$ had significantly lower overall mortality rate when compared with other three groups. In addition, older age, presence of diabetes, lower values of BMI, BP, hemoglobin, TSAT, phosphorus, intact-PTH and albumin, and higher CRP values were associated with a significant increase in overall mortality. In the multivariate analysis, the group with a GNRI $\geq 95.3$ and TG/HDL-C $\geq 2.09$, older age and lower TSAT were associated with overall mortality. Figure 1 illustrated the Kaplan-Meier survival curves for overall survival among the four study groups. The group with a GNRI $\geq 95.3$ and TG/HDL-C $\geq 2.09$ had better overall survival than those with a GNRI $<95.3$ (TG/HDL-C $\geq 2.09$ or TG/HDL-C $<2.09$ ) (logrank test, $\mathrm{p}<0.0001)$.

\subsection{Risk of CV Mortality}

Of those who died due to $\mathrm{CV}$ causes during the follow-up period, 30 died due to heart failure, 11 due to cerebrovascular diseases, 6 due to myocardial infarction, 


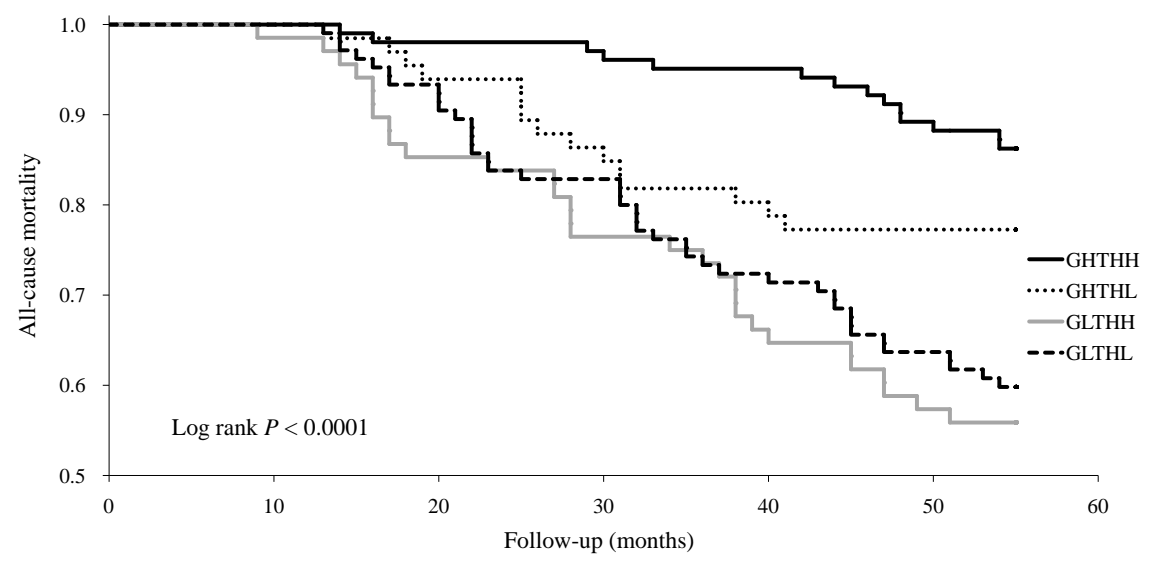

Figure 1. Kaplan-Meier analyses of overall survival among 4 study groups. GHTHH: GNRI $\geq 95.3$ and TG/HDL $\geq 2.09$; GHTHL: GNRI $\geq 95.3$ and TG/HDL $<2.09$; GLTHH: GNRI $<95.3$ and TG/HDL $\geq 2.09$; GLTHL: GNRI $<95.3$ and TG/HDL $<2.09$.

Table 1. Baseline characteristics of the study population.

\begin{tabular}{|c|c|c|c|c|c|c|}
\hline & $\begin{array}{c}\text { All patient } \\
(\mathrm{n}=341)\end{array}$ & $\begin{array}{c}\text { GNRI } \geq 95.3 \text { and } \\
\text { TG/HDL } \geq 2.09 \\
(\mathrm{n}=102)\end{array}$ & $\begin{array}{c}\text { GNRI } \geq 95.3 \text { and } \\
\text { TG/HDL }<2.09 \\
(n=66)\end{array}$ & $\begin{array}{c}\text { GNRI }<95.3 \text { and } \\
\text { TG/HDL } \geq 2.09 \\
(n=68)\end{array}$ & $\begin{array}{c}\text { GNRI }<95.3 \text { and } \\
\text { TG/HDL }<2.09 \\
\mathrm{~N}=105\end{array}$ & $\mathrm{p}$-value \\
\hline Age, years & $65.5 \pm 13.2$ & $61.3 \pm 11.8$ & $62.4 \pm 14.0$ & $69.3 \pm 13.0$ & $69.0 \pm 12.5$ & $<0.0001$ \\
\hline Female, \% & 36.4 & 30.4 & 31.8 & 41.18 & 41.9 & 0.2372 \\
\hline Dialysis vintage, years & $5.1 \pm 6.3$ & $4.8 \pm 6.4$ & $5.0 \pm 4.8$ & $4.4 \pm 6.0$ & $5.6 \pm 7.1$ & 0.6002 \\
\hline $\mathrm{Kt} / \mathrm{V}$ & $1.4 \pm 0.2$ & $1.4 \pm 0.2$ & $1.4 \pm 0.2$ & $1.4 \pm 0.3$ & $1.4 \pm 0.3$ & 0.3354 \\
\hline Diabetes, $\%$ & 47.8 & 50.0 & 48.0 & 52.9 & 42.9 & 0.5798 \\
\hline History of previous CVD, \% & 10.6 & 11.8 & 12.1 & 7.4 & 10.5 & 0.7847 \\
\hline BMI, $\mathrm{kg} / \mathrm{m}^{2}$ & $22.2 \pm 3.6$ & $24.4 \pm 3.2$ & $23.3 \pm 3.1$ & $21.3 \pm 3.7$ & $20.1 \pm 2.6$ & $<0.0001$ \\
\hline Systolic BP, mmHg & $153.0 \pm 17.2$ & $153.6 \pm 16.4$ & $155.2 \pm 17.5$ & $152.7 \pm 17.8$ & $151.3 \pm 17.6$ & 0.5293 \\
\hline Diastolic BP, mmHg & $80.1 \pm 11.7$ & $81.7 \pm 10.6$ & $81.1 \pm 13.9$ & $79.0 \pm 11.9$ & $78.5 \pm 11.1$ & 0.1748 \\
\hline Mean BP, mmHg & $104.3 \pm 12.3$ & $105.6 \pm 11.4$ & $105.7 \pm 13.8$ & $103.6 \pm 12.4$ & $102.7 \pm 11.9$ & 0.2454 \\
\hline Pulse pressure, $\mathrm{mmHg}$ & $73.0 \pm 13.4$ & $71.9 \pm 12.2$ & $74.2 \pm 13.7$ & $73.8 \pm 14.3$ & $72.9 \pm 13.7$ & 0.6924 \\
\hline \multicolumn{7}{|l|}{ Laboratory data } \\
\hline nPCR, g/kg/day & $0.8 \pm 0.2$ & $0.8 \pm 0.2$ & $0.9 \pm 0.2$ & $0.8 \pm 0.2$ & $0.9 \pm 0.2$ & 0.2097 \\
\hline Hemoglobin, $\mathrm{g} / \mathrm{dl}$ & $10.7 \pm 1.2$ & $11.0 \pm 1.1$ & $10.8 \pm 1.3$ & $10.6 \pm 1.1$ & $10.4 \pm 1.2$ & 0.0083 \\
\hline Ferritin, ng/mL & $87.0 \pm 94.7$ & $71.4 \pm 85.9$ & $85.4 \pm 83.5$ & $92.3 \pm 86.4$ & $99.7 \pm 112.2$ & 0.1798 \\
\hline TSAT, $\%$ & $24.6 \pm 12.6$ & $23.5 \pm 11.5$ & $28.0 \pm 13.6$ & $23.3 \pm 10.2$ & $24.4 \pm 13.9$ & 0.0930 \\
\hline Calcium (corrected, mg/dl) & $9.1 \pm 0.6$ & $9.1 \pm 0.7$ & $9.1 \pm 0.6$ & $9.2 \pm 0.6$ & $9.2 \pm 0.6$ & 0.5944 \\
\hline Phosphorus, mg/dl & $4.9 \pm 1.6$ & $5.1 \pm 1.5$ & $5.3 \pm 1.6$ & $4.9 \pm 1.7$ & $4.6 \pm 1.7$ & 0.0130 \\
\hline Intact-PTH, pg/ml & $128.4 \pm 131.5$ & $116.4 \pm 96.3$ & $142.9 \pm 109.5$ & $133.2 \pm 177.3$ & $127.9 \pm 139.5$ & 0.6306 \\
\hline Albumin, $g / 1$ & $3.7 \pm 0.3$ & $3.9 \pm 0.2$ & $3.9 \pm 0.2$ & $3.5 \pm 0.2$ & $3.5 \pm 0.3$ & $<0.0001$ \\
\hline $\mathrm{CRP}, \mathrm{mg} / \mathrm{l}$ & $0.4 \pm 0.8$ & $0.3 \pm 0.4$ & $0.2 \pm 0.4$ & $0.5 \pm 0.9$ & $0.5 \pm 1.0$ & 0.0311 \\
\hline Total cholesterol, mg/dl & $151.2 \pm 30.5$ & $156.5 \pm 30.9$ & $142.2 \pm 28.9$ & $153.4 \pm 26.2$ & $150.1 \pm 32.6$ & 0.0245 \\
\hline Triglyceride (TG), mg/dl & $114.4 \pm 74.2$ & $172.2 \pm 78.3$ & $65.6 \pm 23.6$ & $145.6 \pm 75.6$ & $68.9 \pm 21.9$ & $<0.0001$ \\
\hline HDL-C, md/dl & $46.2 \pm 14.2$ & $36.3 \pm 7.4$ & $54.1 \pm 13.2$ & $38.7 \pm 10.2$ & $55.7 \pm 12.9$ & $<0.0001$ \\
\hline Non-HDL-C, mg/l & $105.0 \pm 30.2$ & $120.2 \pm 29.0$ & $88.1 \pm 25.5$ & $114.7 \pm 22.9$ & $94.4 \pm 28.9$ & $<0.0001$ \\
\hline
\end{tabular}

Continuous variables are expressed as means $\pm \mathrm{SD}$. Count data are expressed as percentages. Abbreviations: $C V D$ cardiovascular disease, GNRI geriatric nutritional risk index, $B M I$ body mass index, $B P$ blood pressure, $n P C R$ normalized. Protein catabolic rate, $T S A T$ transferrin saturation, $P T H$ parathyroid hormone, $C R P C$-reactive protein, $H D L$ - $C$ high-density lipoprotein cholesterol. 
Table 2. Relation of study groups to all-cause mortality using Cox proportional hazards model.

\begin{tabular}{|c|c|c|c|c|}
\hline \multirow{2}{*}{ All-cause mortality } & \multicolumn{2}{|c|}{ Univariate } & \multicolumn{2}{|c|}{ Multivariate } \\
\hline & HR (95\% CI) & p-value & HR (95\% CI) & p-value \\
\hline \multicolumn{5}{|c|}{ Study Group } \\
\hline $\mathrm{GNRI} \geq 95.3$ and $\mathrm{TG} / \mathrm{HDL} \geq 2.09$ & 1.00 & - & 1.00 & - \\
\hline $\mathrm{GNRI} \geq 95.3$ and $\mathrm{TG} / \mathrm{HDL}<2.09$ & $1.84(0.88-3.86)$ & 0.1020 & $2.24(1.06-4.76)$ & 0.0340 \\
\hline GNRI $<95.3$ and TG/HDL $\geq 2.09$ & $4.06(2.19-7.90)$ & $<0.0001$ & $2.56(1.24-5.48)$ & 0.0105 \\
\hline GNRI $<95.3$ and $\mathrm{TG} / \mathrm{HDL}<2.09$ & $3.53(1.98-6.71)$ & $<0.0001$ & $2.40(1.19-5.00)$ & 0.0136 \\
\hline Age & $1.06(1.04-1.08)$ & $<0.0001$ & $1.05(1.03-1.07)$ & $<0.0001$ \\
\hline Female sex & $0.93(0.61-1.39)$ & 0.7371 & & \\
\hline Dialysis vintage & $0.99(0.95-1.02)$ & 0.4544 & & \\
\hline $\mathrm{Kt} / \mathrm{v}$ & $0.49(0.22-1.10)$ & 0.0829 & & \\
\hline Diabetes & $1.61(1.09-2.41)$ & 0.0166 & $1.54(1.02-2.34)$ & 0.0382 \\
\hline History of previous CVD, \% & $1.02(0.51-1.82)$ & 0.9588 & & \\
\hline BMI, kg/m² & $0.89(0.84-0.95)$ & 0.0001 & & \\
\hline Systolic BP, mmHg & $0.99(0.98-1.00)$ & 0.0120 & & \\
\hline Diastolic BP, mmHg & $0.97(0.95-0.98)$ & $<0.0001$ & $1.00(0.98-1.02)$ & 0.8761 \\
\hline Mean BP, mmHg & $0.97(0.96-0.99)$ & 0.0002 & & \\
\hline Pulse pressure, $\mathrm{mmHg}$ & $1.00(0.99-1.02)$ & 0.8301 & & \\
\hline \multicolumn{5}{|c|}{ Laboratory data } \\
\hline nPCR, g/kg/day & $0.35(0.12-1.04)$ & 0.0586 & & \\
\hline Hemoglobin, g/dl & $0.85(0.73-0.99)$ & 0.0401 & $1.02(0.85-1.22)$ & 0.8461 \\
\hline Ferritin, ng/ml & $1.00(1.00-1.00)$ & 0.7640 & & \\
\hline TSAT, $\%$ & $0.97(0.96-0.99)$ & 0.0029 & $0.97(0.95-0.99)$ & 0.0067 \\
\hline Calcium, mg/dl; corrected & $1.21(0.90-1.61)$ & 0.2090 & & \\
\hline Phosphorus, mg/dl & $0.88(0.78-1.00)$ & 0.0466 & $0.99(0.87-1.14)$ & 0.9294 \\
\hline Intact-PTH, pg/ml & $1.00(1.00-1.00)$ & 0.0451 & $1.00(1.00-1.00)$ & 0.3671 \\
\hline Albumin, g/l & $0.27(0.16-0.47)$ & $<0.0001$ & $0.81(0.35-1.95)$ & 0.6367 \\
\hline $\mathrm{CRP}, \mathrm{mg} / \mathrm{l}$ & $1.26(1.03-1.48)$ & 0.0267 & $1.03(0.83-1.24)$ & 0.7391 \\
\hline Total cholesterol, mg/dl & $1.00(0.99-1.00)$ & 0.6643 & & \\
\hline Triglyceride, mg/dl & $1.00(0.99-1.00)$ & 0.0064 & & \\
\hline $\mathrm{HDL}-\mathrm{C}, \mathrm{md} / \mathrm{dl}$ & $1.01(1.00-1.02)$ & 0.1837 & & \\
\hline Non-HDL-C, mg/l & $1.00(0.99-1.00)$ & 0.2860 & & \\
\hline
\end{tabular}

and 5 due to arrhythmia. The Cox proportional hazard regression analysis of the four groups for $\mathrm{CV}$ mortality is shown in Table 3. The univariate regression analysis shows that the group with a GNRI $\geq 95.3$ and TG/HDL-C $\geq 2.09$ had significantly lower CV mortality rate when compared with other three groups. In addition, older age, lower mean BP and lower albumin were associated with CV mortality. In the multivariate analysis, the group with a GNRI $\geq 95.3$ and TG/HDL-C $\geq 2.09$, older age and lower mean BP were associated with CV mortality. Figure 2 shows the Kaplan-Meier survival curves for CV mortality among the four study groups. The group with a GNRI $\geq 95.3$ and TG/HDL-C $\geq 2.09$ had better CV survival than those with other three groups. 


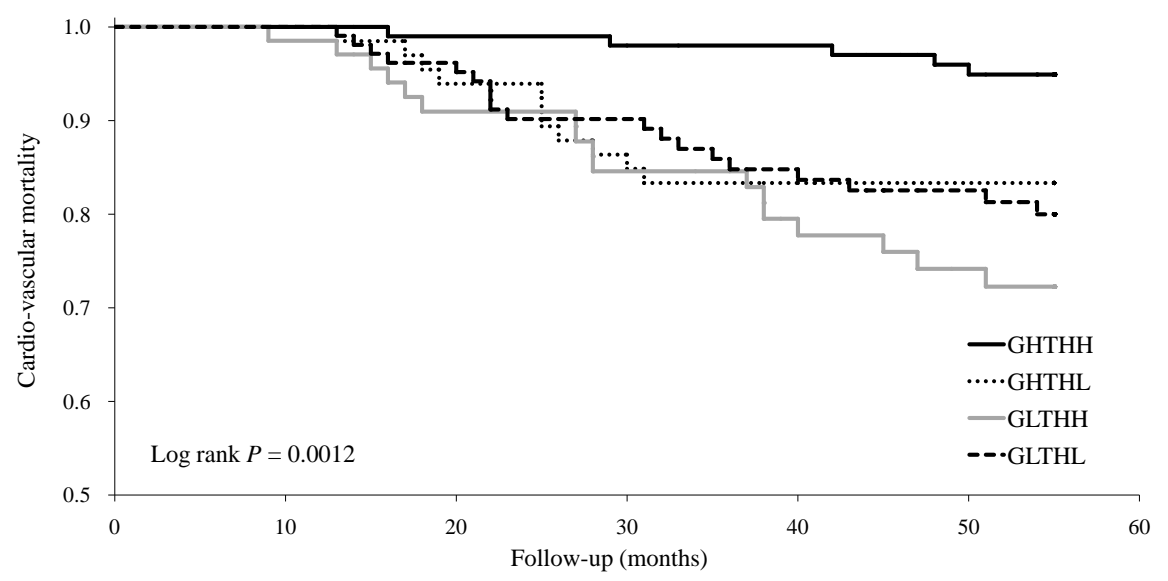

Figure 2. Kaplan-Meier analyses of cardiovascular survival among 4 study groups. GHTHH: GNRI $\geq 95.3$ and TG/HDL $\geq 2.09$; GHTHL: GNRI $\geq 95.3$ and TG/HDL $<2.09$; GLTHH: GNRI $<95.3$ and TG/HDL $\geq 2.09$; GLTHL: GNRI $<95.3$ and TG/HDL $<2.09$.

Table 3. Relation of study groups to cardiovascular mortality using Cox proportional hazards model

\begin{tabular}{|c|c|c|c|c|}
\hline \multirow{2}{*}{ Cardiovascular death } & \multicolumn{2}{|c|}{ Univariate } & \multicolumn{2}{|c|}{ Multivariate } \\
\hline & HR $(95 \%$ CI $)$ & p-value & HR (95\% CI) & p-value \\
\hline \multicolumn{5}{|c|}{ Study Group } \\
\hline $\mathrm{GNRI} \geq 95.3$ and $\mathrm{TG} / \mathrm{HDL} \geq 2.09$ & 1.00 & - & 1.00 & - \\
\hline $\mathrm{GNRI} \geq 95.3$ and $\mathrm{TG} / \mathrm{HDL}<2.09$ & $3.72(1.35-11.80)$ & 0.0105 & $3.83(1.39-12.17)$ & 0.0092 \\
\hline GNRI $<95.3$ and TG/HDL $\geq 2.09$ & $6.25(2.47-19.01)$ & $<0.0001$ & $3.56(1.24-11.89)$ & 0.0178 \\
\hline GNRI $<95.3$ and TG/HDL $<2.09$ & $4.35(1.75-13.12)$ & 0.0011 & $2.55(0.90-8.40)$ & 0.0796 \\
\hline Age & $1.06(1.04-1.09)$ & $<0.0001$ & $1.04(1.01-1.07)$ & 0.0043 \\
\hline Female sex & $1.10(0.62-1.91)$ & 0.7339 & & \\
\hline Dialysis vintage & $0.97(0.91-1.02)$ & 0.1979 & & \\
\hline $\mathrm{Kt} / \mathrm{v}$ & $0.34(0.12-1.04)$ & 0.0579 & & \\
\hline $\mathrm{DM}$ & $1.61(0.94-2.83)$ & 0.0857 & & \\
\hline History of previous CVD, \% & $0.69(0.21-1.68)$ & 0.4445 & & \\
\hline BMI, $\mathrm{kg} / \mathrm{m}^{2}$ & $0.94(0.87-1.02)$ & 0.1590 & & \\
\hline Systolic BP, mmHg & $0.97(0.96-0.99)$ & 0.0010 & & \\
\hline Diastolic BP, mmHg & $0.96(0.93-0.98)$ & 0.0001 & & \\
\hline Mean BP, mmHg & $0.96(0.94-0.98)$ & $<0.0001$ & $0.97(0.95-1.00)$ & 0.0210 \\
\hline Pulse pressure, $\mathrm{mmHg}$ & $0.99(0.97-1.01)$ & 0.2846 & & \\
\hline \multicolumn{5}{|c|}{ Laboratory data } \\
\hline nPCR, g/kg/day & $0.23(0.05-1.07)$ & 0.0609 & & \\
\hline Hemoglobin, g/dl & $0.89(0.72-1.12)$ & 0.3121 & & \\
\hline Ferritin, ng/ml & $1.00(1.00-1.00)$ & 0.7979 & & \\
\hline TSAT, $\%$ & $0.99(0.96-1.01)$ & 0.2137 & & \\
\hline Calcium, mg/dl; corrected & $1.31(0.86-1.93)$ & 0.2007 & & \\
\hline Phosphorus, mg/dl & $0.88(0.74-1.04)$ & 0.1323 & & \\
\hline Intact-PTH, pg/ml & $1.00(0.99-1.00)$ & 0.0704 & & \\
\hline Albumin, g/l & $0.30(0.14-0.67)$ & 0.0036 & $0.61(0.19-2.08)$ & 0.4277 \\
\hline $\mathrm{CRP}, \mathrm{mg} / \mathrm{l}$ & $1.30(1.00-1.60)$ & 0.0536 & & \\
\hline Total cholesterol, mg/dl & $1.00(0.99-1.01)$ & 0.8668 & & \\
\hline Triglyceride, mg/dl & $1.00(0.99-1.00)$ & 0.3844 & & \\
\hline $\mathrm{HDL}-\mathrm{C}, \mathrm{md} / \mathrm{dl}$ & $1.01(0.99-1.03)$ & 0.2887 & & \\
\hline Non-HDL-C, mg/l & $1.00(0.99-1.01)$ & 0.5009 & & \\
\hline
\end{tabular}




\section{Discussion}

The results of this study showed that the combination of the GNRI and the TG/HDL-C ratio was predictive of all-cause mortality and CV deaths in MHD patients. Stratification of the severity of malnutrition and dyslipidemia in MHD patients should be recognized as a reliable available tool for predicting long-term survival of MHD patients.

The assessment and monitoring of protein and energy nutritional statuses are essential in the prevention, diagnosis and treatment of uremic malnutrition in dialysis patients [15]. As no definitive single, gold-standard test is currently available to assess nutritional status, a number of different tools are required. Many nutritional screening tools have been developed for the elderly, children, hospitalized patients, community patients, and/or patients with cancer or infections. Some of them may be safely and easily applied to patients on maintenance HD as well [16]. The Subjective Global Nutritional Assessment is a well validated clinical tool for screening malnutrition [17] and the malnutrition-inflammation score (MIS) is able to predict mortality and hospitalization in maintenance HD patients [18]. However, both require subjective assessment and judgment by a skilled examiner.

The GNRI consists of few objective components, including serum albumin and BMI and represents a simple nutritional screening tool. Takahashi et al. [19] have recently demonstrated that GNRI at initiation of HD therapy could predict CV mortality with incremental predictability compared to serum albumin and BMI in HD patients. Although the lowest GNRI quartile $(<92)$ is strongly associated with malnutrition signs and in addition to an increased risk of overall mortality, no predictive value emerged regarding non-fatal CV events in HD patients. In previously conducted study, we have demonstrated that GNRI was one of the parameters as a predictor of overall mortality [20]. However, CV mortality was not associated with GNRI values, and did not differ among the GNRL quartiles. The GNRI can be considered a simple and reliable marker of predictor for mortality risk in Japanese MHD patients. The GNRI has been shown able to predict increased future healthcare costs and a higher risk of hospitalization in independent-living older adults; so it can be considered to be a rapid and lowcost tool that has the potential to be routinely used in regular population-based settings.

HD patients have unique lipid profiles, and the associations between their lipid profiles and $\mathrm{CV}$ outcomes and mortality are different from the associations in the general population [21]. Kilpatrick et al. [21] demonstrated that HDL-C and TG did not to predict CV or all-cause mortality in a large HD cohort who were followed up for 3 years. We previously used the TG/HDL-C ratio to predict all-cause mortality and CV events, and the results clearly demonstrated the predictive power of the TG/HDL-C ratio in MHD patients [22]. Chen et al. [23] have recently demonstrated the predictive ability of the TG/HDL-C ratio for CV outcomes and survival in patients undergoing prevalent dialysis. The TG/HDL$\mathrm{C}$ ratio may therefore be the optimal marker for predicting $\mathrm{CV}$ outcomes in 
MHD patients.

The mechanisms underlying the association between the combination of GNRI and TG/HDL-C ratios and all-cause mortality and CV deaths in MHD patients are still unknown. Multiple mechanisms may explain the link between malnutrition and mortality in renal failure, including derangements in muscle, adipose tissue, gastrointestinal, hematopoietic and immune systems, and abnormal activation of the inflammatory process [24], in addition to co-morbidities. Low albumin, cholesterol, and BMI are indicators of protein-energy wasting (PEW), but they may not be causally responsible for the negative outcome. The reduction in muscle mass, namely sarcopenia, observed in PEW may be due to uremic toxins or procatabolic conditions (metabolic, hormonal, or neuropathic derangements, including inactivity). In turn, muscle wasting may lead to reduced skeletal, respiratory, and cardiac muscle function, causing functional insufficiency and then risk of severe events [24].

We have previously reported an interaction between the TG/HDL-C ratio and $\mathrm{DM}$ in the prediction of CV events [22]. This finding is also consistent with the interaction exists between them in predicting events in the general population, and patients with a high TG/HDL-C ratio have been reported to be predisposed to diabetes mellitus [25]. The diabetic status of patients with both diabetes and dyslipidemia is crucial when assessing CV outcomes compared with non-diabetic patients with dyslipidemia. As shown in a clinical study [26], the manipulation of high TG and low HDL-C levels in diabetic patients by medical interventions does not reduce their risk of $\mathrm{CV}$ outcomes. Consequently, the utility of the TG/HDL-C ratio for predicting long-term CV outcomes in diabetic MHD patients needs to be carefully assessed in further large-scale investigations.

The present study had several limitations. Firstly, the observational nature of the study precludes drawing conclusions about causal relationships. Secondly, the measurement of alternative nutritional markers and the specific lipoproteins related to atherogenic dyslipidemia was not taken, and as such, the relationship between TG/HDL-C ratios and apolipoproteins in MHD patients needs to be investigated further. Thirdly, this was a single-center study, and all of the participants were Japanese in addition to being treated by the same physicians. The same uniform laboratory tetsts were performed during the observation period, which guaranteed the accuracy of our results, but our conclusions cannot be generalized to other ethnicities.

\section{Conclusion}

The results of this study suggest that the combination of the GNRI and the TG/HDL-C ratio can independently predict all-cause mortality and CV deaths in MHD patients, especially in diabetic MHD patients.

\section{Acknowledgements}

The authors thank all the participants and Mr. Tomonori Kimura and Mr. Toshiaki Naganuma at Jyoban Hospital for clinical data screening. 


\section{Disclosure}

All authors have no conflicts of interest to declare.

\section{References}

[1] Yamada, K., Furuya, R., Takita, T., Maruyama, Y., Yamaguchi, Y., Ohkawa, S., et al. (2008) Simplified Nutritional Screening Tools for Patients on Maintenance Hemodialysis. American Journal of Clinical Nutrition, 87, 106-113.

[2] Kobayashi, I., Ishimura, E., Kato, Y., Okuno, S., Yamamoto, T., Yamakawa, T., et al. (2010) Geriatric Nutritional Risk Index, a Simplified Nutritional Screening Index, Is a Significant Predictor of Mortality in Chronic Dialysis Patients. Nephrology Dialysis Transplant, 25, 3361-3365. https://doi.org/10.1093/ndt/gfq211

[3] Park, J.H., Kim, S.B., Shin, H.S., Jung, Y.S. and Rim, H. (2012) Geriatric Nutritional Risk Index May Be a Significant Predictor of Mortality in Korean Hemodialysis Patients: A Single Center Study. Therapeutic Apheresis and Dialysis, 16, 121-126. https://doi.org/10.1111/j.1744-9987.2011.01046.x

[4] Ballantyne, C.M., Olsson, A.G., Cook, T.J., Mercuri, M.F., Pedersen, T.R. and Kjekshus, J. (2001) Influence of Low High-Density Lipoprotein Cholesterol and Elevated Triglyceride on Coronary Heart Disease Events and Response to Simvastatin Therapy in 4S. Circulation, 104, 3046-3051. https://doi.org/10.1161/hc5001.100624

[5] Manninen, V., Tenkanen, L., Koskinen, P., Huttunen, J.K., Manttari, M., Heinonen, O.P., et al. (1992) Joint Effects of Serum Triglyceride and LDL Cholesterol and HDL Cholesterol Concentrations on Coronary Heart Disease Risk in the Helsinki Heart Study. Implications for Treatment. Circulation, 85, 37-45.

https://doi.org/10.1161/01.CIR.85.1.37

[6] Frohlich, J. and Dobiasova, M. (2003) Fractional Esterification Rate of Cholesterol and Ratio of Triglycerides to HDL-Cholesterol Are Powerful Predictors of Positive Findings on Coronary Angiography. Clinical Chemistry, 49, 1873-1880.

https://doi.org/10.1373/clinchem.2003.022558

[7] McLaughlin, T., Reaven, G., Abbasi, F., Lamendola, C., Saad, M., Waters, D., et al. (2005) Is There a Simple Way to Identify Insulin-Resistant Individuals at Increased Risk of Cardiovascular Disease? American Journal of Cardiology, 96, 399-404. https://doi.org/10.1016/j.amjcard.2005.03.085

[8] Gaziano, J.M., Hennekens, C.H., O’Donnell, C.J., Breslow, J.L. and Buring, J.E. (1997) Fasting Triglycerides, High-Density Lipoprotein, and Risk of Myocardial Infarction. Circulation, 96, 2520-2525. https://doi.org/10.1161/01.CIR.96.8.2520

[9] Jeppesen, J., Hein, H.O., Suadicani, P. and Gymtelberg, F. (2001) Low TriglyceridesHigh High-Density Lipoprotein Cholesterol and Risk of Ischemic Heart Disease. Archives of Internal Medicine, 161, 361-366. https://doi.org/10.1001/archinte.161.3.361

[10] Barzi, F., Patel, A., Woodward, M., Lawes, C.M., Ohkubo, T., Gu, D., et al. (2005) A Comparison of Lipid Variables as Predictors of Cardiovascular Disease in the Asia Pacific Region. Annals of Epidemiology, 15, 405-413.

https://doi.org/10.1016/j.annepidem.2005.01.005

[11] Bittner, V., Johnson, B.D., Zineh, I., Rogers, W.J., Vido, D., Marroquin, O.C., et al. (2009) The Triglyceride/High-Density Lipoprotein Cholesterol Ratio Predicts All-Cause Mortality in Women with Suspected Myocardial Ischemia: A Report from the Women's Ischemia Syndrome Evaluation (WISE). American Heart Journal, 157, 548-555. https://doi.org/10.1016/j.ahj.2008.11.014

[12] Daugirdas, J.T. (1993) Second Generation Logarithmic Estimates of Single-Pool Va- 
riable Volume Kt/V: An Analysis of Error. Journal of American Society of Nephrology, 4, 1205-1213.

[13] Shinzato, T., Nakai, S., Fujita, Y., Takai, I., Morita, H., Nakane, K., et al. (1994) Determination of Kt/V and Protein Catabolic Rate Using Pre- and Post-Dialysis Blood Urea Nitrogen Concentrations. Nephron, 67, 280-290.

https://doi.org/10.1159/000187980

[14] Examination Committee of Criteria for "Obesity Disease" in Japan and Japan Society for the Study of Obesity (2002) New Criteria for Obesity Disease in Japan. Circulation Journal, 66, 987-992. https://doi.org/10.1253/circj.66.987

[15] Nitta, K. and Tsuchiya, K. (2016) Recent Advances in the Pathophysiology and Management of Protein-Energy Wasting in Chronic Kidney Disease. Renal Replacement Therapy, 2, 4. https://doi.org/10.1186/s41100-016-0015-5

[16] Kalantar-Zadeh, K., Kopple, J.D., Humphreys, M.H. and Block, G. (2004) Comparing Outcome Predictability of Markers of Malnutrition-Inflammation Complex Syndrome in Hemodialysis Patients. Nephrology Dialysis Transplantation, 19, 1507-1519. https://doi.org/10.1093/ndt/gfh143

[17] De Mutsert, R., Grootendorst, D.C., Axelsson, J., Boeschoten, E.W., Krediet, R.T., et al. (2008) Excess Mortality to Interaction between Protein-Energy Wasting, Inflammation and Cardiovascular Disease in Chronic Dialysis Patients. Nephrology Dialysis Transplantation, 23, 2957-2964. https://doi.org/10.1093/ndt/gfn167

[18] Baumeister, S.E., Fischer, B., Doring, A., Koenig, W., Zierer, A., et al. (2011) The Geriatric Nutritional Risk Index Predicts Increased Healthcare Costs and Hospitalization in a Cohort of Community-Dwelling Older Adults: Results from the Monica/Kora Augsburg Cohort Study, 1994-2005. Nutrition, 27, 534-542. https://doi.org/10.1016/j.nut.2010.06.005

[19] Takahashi, H., Ito, Y., Ishii, H., Aoyama, T., Kamoi, D., Kasuga, H., et al. (2014) Geriatric Nutritional Risk Index Accurately Predicts Cardiovascular Mortality in Incident Hemodialysis Patients. Journal of Cardiology, 64, 32-36. https://doi.org/10.1016/j.jjcc.2013.10.018

[20] Komatsu, M., Okazaki, M., Tsuchiya, K., Kawaguchi, H. and Nitta, K. (2015) Geriatric Nutritional Index Is Simple Predictor of Mortality in Chronic Hemodialysis Patients. Blood Purification, 39, 281-287. https://doi.org/10.1159/000381798

[21] Kilpatrick, R.D., McAllister, C.J., Kovesdy, C.P., Derose, S.F., Kopple, J.D. and Kalantar-Zadeh, K. (2007) Association between Serum Lipids and Survival in Hemodialysis Patients and Impact of Race. Journal of American Society of Nephrology, 18, 293-303. https://doi.org/10.1681/ASN.2006070795

[22] Hasegawa, A., Kojima, F., Ueda, M., Tanaka, Y. and Nitta, K. (2016) Triglyceride to High-Density Lipoprotein Cholesterol Ratio Predicts Cardiovascular Events in Maintenance Hemodialysis Patients. Renal Replacement Therapy, 2, 60.

https://doi.org/10.1186/s41100-016-0069-4

[23] Chen, H.Y., Tsai, W.C., Chiu, Y.L., Hsu, S.P., Pai, M.E., et al. (2015) Triglyceride to High-Density Lipoprotein Cholesterol Ratio Predicts Cardiovascular Outcomes in Prevalent Dialysis Patients. Medicine (Baltimore), 94, e619.

https://doi.org/10.1097/MD.0000000000000619

[24] Carrero, J.J., Stenvinkel, P., Cuppari, L., Ikizler, T.A., Kalantar-Zadeh, K., Kaysen, G., et al. (2013) Etiology of the Protein-Energy Wasting Syndrome in Chronic Kidney Disease: A Consensus Statement from the International Society of Renal Nutrition and Metabolism (ISRNM). Journal of Renal Nutrition, 23, 77-90. https://doi.org/10.1053/j.jrn.2013.01.001

[25] AIM-HIGH Investigators (2011) The Role of Niacin in Raising High-Density Lipo- 
protein Cholesterol to Reduce Cardiovascular Events in Patients with Atherosclerotic Cardiovascular Disease and Optimally Treated Low-Density Lipoprotein Cholesterol: Baseline Characteristics of Study Participants. The Atherothrombosis Intervention in Metabolic Syndrome with Low Hdl/High Triglycerides: Impact on Global Health Outcomes (AIM-HIGH) Trial. American Heart Journal, 161, 538543. https://doi.org/10.1016/j.ahj.2010.12.007

[26] Keech, A., Simes, R.J., Barter, P., Best, J., Scott, R., Taskinen, M.R., et al. (2005) Effects of Long-Term Fenofibrate Therapy on Cardiovascular Events in 9795 People with Type 2 Diabetes Mellitus (the FIELD Study): Randomized Controlled Trial. The Lancet, 366, 1849-1861. https://doi.org/10.1016/S0140-6736(05)67667-2

Submit or recommend next manuscript to SCIRP and we will provide best service for you:

Accepting pre-submission inquiries through Email, Facebook, LinkedIn, Twitter, etc. A wide selection of journals (inclusive of 9 subjects, more than 200 journals) Providing 24-hour high-quality service User-friendly online submission system Fair and swift peer-review system Efficient typesetting and proofreading procedure Display of the result of downloads and visits, as well as the number of cited articles Maximum dissemination of your research work

Submit your manuscript at: http://papersubmission.scirp.org/ Or contact ijcm@scirp.org 